\title{
Superação de dormência de sementes e desenvolvimento de mudas de jatobazeiro em substratos alternativos
}

\author{
Patrícia Rodrigues Maffud Carvalho ${ }^{1}$, César Antônio da Silva ${ }^{2}$, Luís Léssi dos Reis ${ }^{3}$, Janaina Rodrigues Maffud ${ }^{1}$ \\ ${ }^{1}$ Instituto Federal do Mato Grosso, IFMT, MT. ${ }^{2}$ Isntituto Federal Goiano - IF Goiano, GO. Instituto Federal do Sul de \\ Minas Gerais - IFSul de Minas, MG. E-mail: cesar.ufu@gmail.com
}

\section{Resumo}

A propagação do jatobazeiro (Hymenaea courbaril L.) por sementes é altamente promissora na recuperação de áreas degradadas. Assim, o presente trabalho teve como objetivo comparar métodos de superação de dormência em sementes de jatobazeiro e avaliar o desenvolvimento de mudas desta espécie em substratos alternativos. No primeiro experimento, em viveiro telado, utilizou-se o delineamento inteiramente casualizado, com quatro repetições e sete tratamentos de sementes: escarificação com ácido sulfúrico, escarificação com lixa (EL), EL e imersão em água por 24 h, EL e imersão em água por 48 h, semente intacta (SI), SI imersa em água por $48 \mathrm{~h}$ e SI imersa em água por $96 \mathrm{~h}$. A contagem das plântulas que emergiam foi realizada em dias alternados, de 13 a 51 dias após a semeadura, quantificando o percentual de emergência, o índice de velocidade de emergência (IVE) e o tempo médio de emergência. O segundo experimento, em casa de vegetação, foi constituído de três repetições, em blocos ao acaso, sendo utilizados sete substratos: substrato comercial (SC); $40 \%$ SC + 60\% húmus de mata (HM); $40 \%$ SC + 60\% casca de arroz carbonizada (CAC); $40 \%$ SC + 60\% esterco bovino (EB); $40 \%$ CAC + 60\% EB; $40 \%$ CAC + 60\% HM; e $40 \%$ HM + 60\% EB. Aos 50, 70 e 120 dias após semeadura foram avaliados: altura de muda, número de folhas, diâmetro de caule, matéria fresca e seca da parte aérea e de raízes, e área foliar. Aos 120 dias, avaliou-se também o índice de clorofila. A escarificação com lixa e imersão das sementes em água por 24 horas apresentou maior emergência $(96,4 \%$ e IVE $=0,697)$. A mistura de $40 \% \mathrm{HM}+60 \%$ EB originou mudas de maior área foliar, índice de clorofila e matéria seca de raízes e parte aérea, aos 120 dias após semeadura.

Palavras-chave: escarificação; Hymenaea courbaril L.; velocidade de emergência.

\section{Overcoming seed dormancy and jatoba seedlings development on alternative substrates}

\begin{abstract}
The propagation of the jatoba (Hymenaea courbaril L.) by seeds is highly promising in the recovery of degraded areas. Thus, the present research aimed to compare methods for jatoba plant seeds dormancy overcoming and to evaluate the development of seedlings of this species in alternative substrates. In the first experiment, in screened nursery, a completely randomized design was used, with four replications and seven seed treatments: scarification with sandpaper (SS), SS and immersion in water for $24 \mathrm{~h}$, SS and immersion in water for $48 \mathrm{~h}$, intact seed, seed immersed in water for $48 \mathrm{~h}$ and seed immersed in water for $96 \mathrm{~h}$. The seedlings that emergency were counted every other days, from 13 to 51 days after sowing, quantifying the emergence percentage, the emergence speed index and the emergence average time. The second experiment, in greenhouse, was composed of three replicates, in randomized blocks, being seven substrates were used: commercial substrate (CS); $40 \%$ SC $+60 \%$ forest humus (FH); $40 \%$ SC $+60 \%$ charcoal rice husk (CRH); 40\% SC + 60\% bovine manure (BM); 40\% CRH + 60\% BM; $40 \% \mathrm{CRH}+60 \% \mathrm{FH}$; e $40 \% \mathrm{FH}+$ $60 \%$ BM. At 50, 70 and 120 days after sowing were evaluated the parameters: seedling height, leafs number, stem diameter, fresh matter and dry matter of aerial part and roots, and leaf area. At 120 DAS, the chlorophyll index was also evaluated. The scarification with sandpaper and immersion of seeds in water for 24 hours presented a greater emergence $(96.4 \%$ and IVE $=0.697)$. The mixture containing $40 \% \mathrm{FH}$ and $60 \%$ BM resulted seedlings with a larger leaf area, chlorophyll index and roots and aerial part dry matter, at 120 days after sowing.
\end{abstract}

Keywords: scarification; Hymenaea courbaril L.; emergence speed. 


\section{Introdução}

O jatobazeiro (Hymenaea courbaril L.) é uma espécie arbórea da família Fabaceae, encontrado em toda a América. No Brasil, essa árvore se encontra do Piauí até o norte do Paraná, e se desenvolve em floresta semidecídua. Os frutos são utilizados na indústria alimentícia e as folhas e sementes na indústria farmacêutica e cosmética (FARIAS et al., 2006). É uma espécie promissora que se destaca tanto pela produção de madeira, que pode ser usada na construção civil e fabricação de móveis, em virtude da alta resistência ao ataque de fungos, quanto pela sua indicação na recuperação de matas ciliares (LAHR et al., 2016; FERREIRA et al., 2016).

Diante da necessidade de reflorestamento de áreas degradadas estabelecida pelo Código Florestal Brasileiro, a propagação de espécies nativas via sementes é fundamental, visando a recomposição florestal. Dentre os vários fatores limitantes, um atinge diretamente a produção de mudas, que é o processo de dormência das sementes (FREITAS et al., 2013).

A impermeabilidade do tegumento, 0 embrião imaturo e a presença de substâncias inibidoras são as principais causas de dormência de sementes florestais. Em sementes de jatobazeiro, a dormência é causada pelo tegumento resistente e impermeável (SOUZA; SEGATO, 2016), o qual impede a entrada de água e trocas gasosas, dificultando a embebição da semente e oxigenação do embrião.

Segundo Busatto et al. (2013), as técnicas mais utilizadas para se fazer a superação de dormência são: escarificação com lixa, abrasão em superfícies ásperas, tratamentos térmicos e químicos, como água quente, ácido clorídrico, ácido sulfúrico e hidróxido de sódio. Nesse sentido algumas técnicas de superação de dormência podem ser mais eficientes que outras, reduzindo o tempo de produção de mudas e, consequentemente, os custos com água, mão de obra e energia nos viveiros.

Conforme Andrade et al. (2010), sementes escarificadas de $H$. courbaril, independentemente da posição de escarificação, com ou sem embebição, apresentaram percentuais de emergência de 58,7 a $80,0 \%$, e índice de velocidade de emergência variando de 0,52 a 0,80 . Outros aspectos a serem observados, são as melhores condições para a germinação de sementes, sendo de elevada importância fatores como água, luz, temperatura e oxigênio, associados ao tipo de substrato utilizado para a germinação e formação das mudas (SAMPAIO et al., 2015; DUARTE et al., 2016).

A composição do substrato é um dos aspectos que mais interfere na produção de mudas de qualidade, em razão de sua densidade aparente, relação $\mathrm{C} / \mathrm{N}$, saturação de bases, $\mathrm{pH}$, disponibilidade de água e nutrientes, como nitrogênio, fósforo, potássio, cálcio e magnésio (ROS et al., 2015; MONACO et al., 2020). O substrato influencia no volume do sistema radicular e no estado nutricional das plantas e, consequentemente, no tempo para transplantio e no pegamento das mudas no campo (CARVALHO FILHO et al., 2003).

Segundo Nascimento et al. (2011), o jatobazeiro apresenta baixo requerimento nutricional e hídrico do substrato na fase inicial, possivelmente devido à presença de substâncias de reserva nos cotilédones. As informações sobre exigências nutricionais de espécies florestais, especialmente as nativas, são escassas, independentemente da fase fenológica.

Diante disso, este trabalho teve como objetivo comparar métodos de superação de dormência em sementes de jatobazeiro (Hymenaea courbaril L.) e avaliar o desenvolvimento de mudas desta espécie em substratos alternativos.

\section{Material e Métodos}

Dois experimentos foram instalados no Instituto Federal de Mato Grosso, em Confresa, MT, a uma altitude de 233 metros, latitude de $10{ }^{\circ} 38^{\prime} 22^{\prime \prime}$ sul e longitude $51^{\circ} 34^{\prime} 17^{\prime \prime}$ oeste. O primeiro foi conduzido em viveiro, sob cobertura de tela de sombreamento $50 \%$, no período de fevereiro a abril de 2014, e o segundo, em casa de vegetação, no período de setembro de 2014 a janeiro de 2015.

No primeiro experimento, sementes coletadas no município de Santa Terezinha, MT, foram colocadas em recipiente com água, onde permaneceram por 20 minutos, para facilitar a remoção da polpa farinácea. Em seguida, foram lavadas em água corrente e colocadas em bandejas, à temperatura ambiente. As sementes foram beneficiadas e padronizadas quanto ao tamanho e ao formato, descartando as sementes com danos no tegumento.

$O$ delineamento experimental utilizado foi o inteiramente casualizado (DIC), com sete tratamentos e quatro repetições, utilizando 14 
sementes por parcela, considerando a não existência de regra para análises de sementes de jatobá, conforme Farias et al. (2006). Os tratamentos foram: escarificação com ácido sulfúrico; escarificação com lixa, na lateral oposta ao hilo, conforme Coelho e Ribeiro (2018); escarificação com lixa e imersão em água por 24 h, escarificação com lixa e imersão em água por $48 \mathrm{~h}$, semente intacta (testemunha), semente intacta imersa em água por $48 \mathrm{~h}$, e semente intacta imersa em água por $96 \mathrm{~h}$. As sementes tratadas com ácido sulfúrico foram imersas por trinta minutos numa solução de $80 \%$ do ácido e $20 \%$ de água destilada e, em seguida, lavadas em água destilada, conforme Souza e Segato (2016).

Utilizou-se o substrato comercial Bioplant, constituído de casca de pinus, fibra de coco, vermiculita, casca de arroz e nutrientes. A semeadura foi feita em recipientes descartáveis de $300 \mathrm{~mL}$, preenchidos com substrato comercial, de $\mathrm{pH} \mathrm{5,4}( \pm 0,5)$.

A irrigação foi realizada diariamente, mantendo a umidade do substrato próxima à capacidade de campo. As avaliações de emergência foram realizadas a cada dois dias, por meio de contagem das plântulas que emergiam, no período de 13 a 51 dias após a semeadura. Foram avaliados o percentual final de emergência (E), o tempo médio de emergência (TME) e o índice de velocidade de emergência (IVE). Para determinar o IVE, utilizou-se a equação descrita por Maguire (1962):

$$
\text { IVE }=\frac{E 1}{N 1}+\frac{E 2}{N 2}+\ldots+\frac{E n}{N n}
$$

em que: IVE é o índice de velocidade de emergência; E1, E2 e En o número de plântulas normais emergidas na primeira, segunda e última contagem, respectivamente; e N1, N2 e Nn o número de dias da semeadura à primeira, à segunda e à última contagem.

No segundo experimento, todas as sementes receberam o tratamento de escarificação com lixa e imersão em água por 24 $h$, que foi o método mais eficaz na superação de dormência no primeiro experimento. 0 delineamento utilizado foi o de blocos ao acaso, com três repetições e sete tratamentos (substratos alternativos) para produção das mudas em casa de vegetação, sendo 14 mudas por parcela. Os materiais utilizados foram substrato comercial (SC), húmus de mata (HM), casca de arroz carbonizada (CAC) e esterco bovino (EB).

Os substratos foram constituídos, nas seguintes proporções, com base em volume: $100 \%$ SC; $40 \%$ SC + 60\% HM; $40 \%$ SC + 60\% CAC; $40 \% \mathrm{SC}+60 \% \mathrm{~EB} ; 40 \% \mathrm{CAC}+60 \% \mathrm{~EB} ; 40 \% \mathrm{CAC}+$ $60 \% \mathrm{HM}$; e $40 \% \mathrm{HM}+60 \% \mathrm{~EB}$, os quais tiveram amostras submetidas a análises químicas, no Instituto Agronômico de Campinas, antes da semeadura (Tabela 1) e ao término do experimento, aos 120 dias após a semeadura.

Tabela 1. Resultado de análises químicas de macro e micronutrientes, potencial hidrogeniônico (pH) e condutividade elétrica (CE) dos substratos, em antecedência à semeadura.

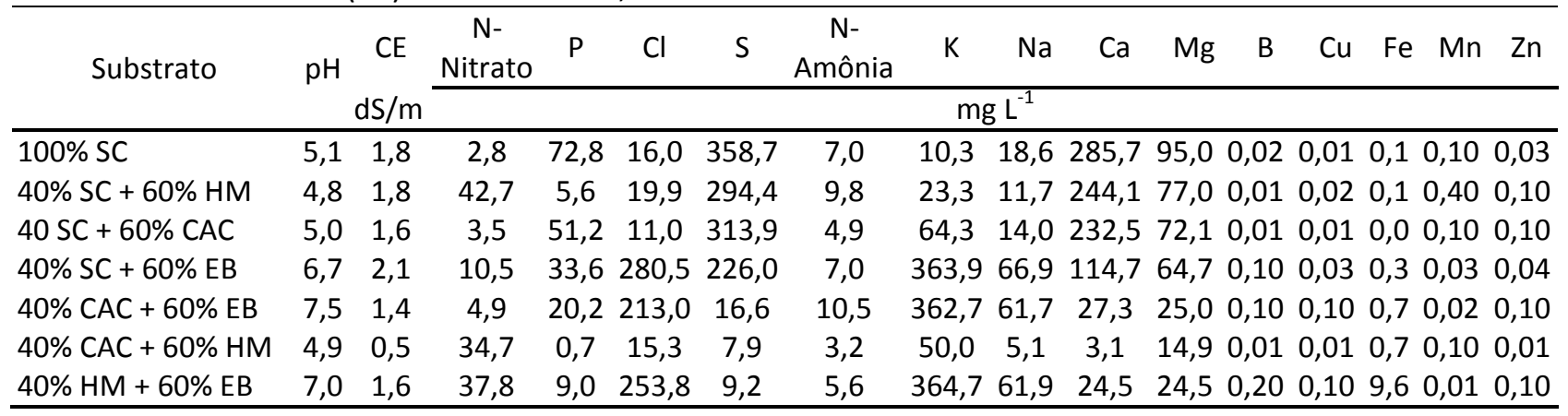

SC - substrato comercial; HM - húmus de mata; CAC - casca de arroz carbonizada; EB - esterco bovino; CE condutividade elétrica; P - fósforo; $\mathrm{Cl}$ - cloro; S - enxofre; N - nitrogênio; $\mathrm{Na}$ - sódio; $\mathrm{Ca}$ - cálcio; $\mathrm{Mg}$ - magnésio; $\mathrm{B}$ boro; $\mathrm{Cu}$ - cobre; Fe - ferro; Mn - manganês; Zn - zinco. Análises realizadas pelo Instituto Agronômico de Campinas.

Recipientes plásticos de $300 \mathrm{~mL}$ foram preenchidos com substrato e, em seguida, realizada a semeadura, em casa de vegetação, em outubro de 2014, mantendo-os em bancada, a 1 metro do solo. Utilizou-se uma semente por recipiente. Após a emergência, aos 25 dias após a semeadura (DAS), realizou-se o transplantio, transferindo apenas plântulas uniformes para sacos plásticos de $15 \times 25 \mathrm{~cm}$, mantidos em casa de vegetação. 
As mudas foram avaliadas aos 50, 70 e 120 DAS. Em cada avaliação, foram escolhidas aleatoriamente quatro mudas por parcela, para determinação de matéria seca.

Os parâmetros avaliados foram: altura de muda (AM, cm), medida com régua, do colo à folha mais nova completamente estendida; número de folhas (NF), contabilizando as folhas unifolioladas e os bifólios; diâmetro de caule (DC, $\mathrm{mm})$, mensurado com paquímetro digital; as massas de matéria fresca de raízes (MFR) e da parte aérea (MFPA), obtidas em balança de precisão; a massa seca de raízes (MSR), da parte aérea (MSPA) e de folhas (MSF), em g muda ${ }^{-1}$, por meio de secagem em estufa de circulação de ar forçado, a $70^{\circ} \mathrm{C}$, até atingir massa constante, e posterior pesagem; a área foliar $\left(\mathrm{AF}, \mathrm{cm}^{2}\right.$ muda $\left.^{-1}\right)$, obtida por meio do método da massa de retângulos foliares (Silva et al., 2016), e o índice de clorofila, medido por meio de clorofilômetro portátil.

Os dados obtidos foram submetidos à análise de variância e teste de Tukey, para a comparação das médias, sendo utilizado o software estatístico SISVAR (FERREIRA, 2011).

\section{Resultados e Discussão \\ Experimento 1}

Houve efeito significativo $(p<0,01)$ dos tratamentos de superação de dormência de sementes em todas os parâmetros analisados. A escarificação das sementes com lixa e imersão em água por 24 e 48 horas foram os métodos que propiciaram maior percentual de emergência (E), não diferindo do método em que as sementes foram apenas escarificadas com lixa (Tabela 2). 0 índice de velocidade de emergência (IVE) e o tempo médio de emergência (TME) apresentaram melhores resultados no lote de sementes escarificadas com lixa e imersas em água. A maior emergência de plântulas nesses tratamentos foi observada no período de 15 a 20 dias após a semeadura. A utilização de ácido sulfúrico também resultou bom resultado de $T M E$, não se diferindo pelo teste de Tukey $(p<0,05)$ da escarificação com lixa, com ou sem imersão em água.

Tabela 2. Percentual de emergência (E), índice de velocidade de emergência (IVE) e tempo médio de emergência (TME) de Hymenaea courbaril L., em função de métodos de superação de dormência de sementes. Confresa-MT, 2014.

\begin{tabular}{lcccc}
\hline \multirow{2}{*}{ Fonte de variação } & \multirow{2}{*}{$\mathrm{GL}$} & \multicolumn{3}{c}{ Fcalculado } \\
\cline { 3 - 5 } & & $\mathrm{E}$ & $\mathrm{IVE}$ & $\mathrm{TME}$ \\
\hline Superação de dormência & 6 & $64,95^{* *}$ & $60,79^{* *}$ & $22,69^{* *}$ \\
Média geral: & & 17,72 & 19,96 & 14,42 \\
\multicolumn{1}{c}{ Superação de dormência } & 54,59 & 0,359 & 29,89 \\
\hline Escarificação com ácido sulfúrico & $\mathrm{E}(\%)$ & $\mathrm{IVE}$ & $\mathrm{TME}$ (dias) \\
Escarificação com lixa & $66,05 \mathrm{~b}$ & $0,400 \mathrm{c}$ & $25,32 \mathrm{a}$ \\
Escarificação com lixa e imersão em água 24 $\mathrm{h}$ & $82,17 \mathrm{ab}$ & $0,497 \mathrm{bc}$ & $23,67 \mathrm{a}$ \\
Escarificação com lixa e imersão em água 48 $\mathrm{h}$ & $96,45 \mathrm{a}$ & $0,697 \mathrm{a}$ & $19,67 \mathrm{a}$ \\
Semente intacta & $91,10 \mathrm{a}$ & $0,662 \mathrm{ab}$ & $20,52 \mathrm{a}$ \\
Semente imersa em água 48 h & $1,77 \mathrm{~d}$ & $0,005 \mathrm{e}$ & $47,00 \mathrm{c}$ \\
Semente imersa em água 96 h & $10,72 \mathrm{~d}$ & $0,057 \mathrm{de}$ & $36,50 \mathrm{~b}$ \\
DMS & $33,90 \mathrm{c}$ & $0,197 \mathrm{~d}$ & $36,50 \mathrm{~b}$ \\
\hline
\end{tabular}

GL - Graus de liberdade. CV - Coeficiente de variação. DMS - Diferença mínima significativa. ** Significativo a $1 \%$ de probabilidade, pelo teste F. ns - Não significativo. Médias seguidas por letras distintas na coluna diferem entre si pelo teste de Tukey, ao nível de $5 \%$ probabilidade.

Resultados semelhantes de emergência foram encontrados por Sampaio et al. (2015) que também avaliaram métodos de superação de dormência em sementes de Hymenaea courbaril L., obtendo maior percentual de emergência, em $84 \%$ das sementes, utilizando escarificação com lixa. O tratamento de apenas escarificação com lixa propiciou percentual de germinação de $82,17 \%$, valor este condizente aos dados obtidos por Cabral et al. (2015). O método proporciona o desgaste do tegumento com a lixa, favorecendo condições para a absorção de água. Assim, estando o substrato úmido, ocorre o processo de 
embebição de água pelos cotilédones e a radícula rompe o tegumento, dando início à germinação.

A escarificação com ácido sulfúrico, imergindo as sementes na solução por 30 minutos, também é vantajosa, apesar de ter observado tempo médio de emergência (TME) cerca de cinco dias a mais, em comparação à escarificação com lixa e imersão em água. Contudo utilização do ácido requer cuidados e riscos de contaminação do meio ambiente. A utilização de sementes intactas demonstrou ser menos eficiente, sendo necessário cerca 47 dias para que a emergência de fato ocorra. Independentemente da imersão ou não em água, por 48 ou 96 horas, a utilização de sementes intactas, requer maior tempo para emergência, em comparação às sementes escarificadas, devido sobretudo à impermeabilidade do tegumento, que, segundo Souza e Segato (2016), impede a entrada de água e trocas gasosas, não ocorrendo o desenvolvimento do embrião.

A utilização de solução de ácido sulfúrico para superação de dormência foi eficiente, apesar de serem observados danos no embrião de sementes que não emergiram. Resultados condizentes foram constatados por Coelho e Ribeiro (2018), ao fazerem a imersão de sementes de jatobá em ácido sulfúrico, por 15 minutos. Teles et al. (2000) utilizaram a escarificação química de sementes de Leucaena leucocephala em ácido sulfúrico, durante 5 a 20 minutos, a qual foi eficaz na superação de dormência, apresentando percentagem de germinação de $82 \%$ e $97 \%$, respectivamente.

Os resultados dos tratamentos físicos e químicos da presente pesquisa em relação à percentagem de emergência de sementes foram condizentes aos obtidos por Sampaio et al. (2015) e Souza e Segato (2016), pois identificaram que os tratamentos com ácido sulfúrico, hidróxido de sódio, imersão em água por 24 horas e escarificação com lixa mostraram-se eficientes na superação da dormência. Por outro lado, Ataíde et al. (2013) verificaram que a imersão de sementes de flamboyant (Delonix regia) em ácido sulfúrico por 15, 30, 45 e 60 minutos propiciaram percentuais de germinação inferiores a $25 \%$, sendo mais eficiente a imersão das sementes em água quente (90 C) por um minuto. A escarificação manual com lixa, na lateral oposta ao hilo da semente, seguida de imersão em água por 24 horas, foi o método mais eficiente na superação de dormência, para os três parâmetros avaliados, sendo mais vantajoso que a escarificação com lixa e imersão em água por 48 horas, pois leva menos tempo. Conforme Souza e Segato (2016), um dos cuidados na escarificação de sementes de Hymenaea courbaril L. com lixa, é que ela deve ser feita do lado oposto à micrópila, evitando possíveis danos na radícula das plântulas.

\section{Experimento 2}

Com relação ao segundo experimento, aos 50 dias após semeadura (Tabela 3 ), houve diferença significativa entre substratos $(p<0,01)$, apenas nos parâmetros de comprimento do sistema radicular (CR) e massa fresca de raízes (MFR). Com relação aos substratos, a mistura de $40 \%$ de casca de arroz carbonizada $+60 \%$ de húmus de mata proporcionou maior MFR, não se diferindo dos substratos $40 \%$ CAC $+60 \%$ EB e $40 \%$ SC $+60 \%$ EB. Tal resultado se deve possivelmente à alta retenção de água, maior disponibilidade de $\mathrm{K}$ e nitrogênio total ( $\mathrm{N}$-nitrato e $\mathrm{N}$-amoniacal) e menor disponibilidade de $\mathrm{P}$, na casca de arroz carbonizada e no esterco bovino, induzindo um maior desenvolvimento do sistema radicular nesses substratos, em relação ao substrato comercial a $100 \%$. 
Tabela 3. Altura de muda (AM), número de folhas (NF), diâmetro do caule (DC), comprimento do sistema radicular (CR), massa fresca da parte aérea (MFPA), massa fresca de raízes (MFR), matéria seca da parte aérea (MSPA), de folhas (MSF) e de raízes (MSR), e área foliar (AF), aos 50 dias após semeadura, em função de substratos. Confresa- MT, 2015.

\begin{tabular}{|c|c|c|c|c|c|c|c|c|c|c|c|}
\hline \multirow{3}{*}{$\begin{array}{l}\text { Fonte de } \\
\text { variação }\end{array}$} & \multirow{3}{*}{$\mathrm{GL}$} & \multicolumn{10}{|c|}{ Fcalculado } \\
\hline & & \multirow{2}{*}{$\begin{array}{l}\text { AM } \\
(\mathrm{cm})\end{array}$} & \multirow{2}{*}{ NF } & \multirow{2}{*}{$\begin{array}{c}\mathrm{DC} \\
(\mathrm{mm})\end{array}$} & \multirow{2}{*}{$\begin{array}{l}\text { CR } \\
(\mathrm{cm})\end{array}$} & \multirow{2}{*}{ MFPA } & MFR & MSPA & MSF & MSR & \multirow{2}{*}{$\begin{array}{c}A F \\
\left(\mathrm{~cm}^{2}\right)\end{array}$} \\
\hline & & & & & & & 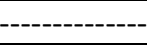 & -g muda & & ------- & \\
\hline Substratos & 6 & $1,15^{\mathrm{ns}}$ & $1,84^{\mathrm{ns}}$ & $0,86^{\mathrm{ns}}$ & $9,45 * *$ & $1,35^{\mathrm{ns}}$ & $10,74 * *$ & $1,92^{\mathrm{ns}}$ & $1,91^{\mathrm{ns}}$ & $1,86^{\mathrm{ns}}$ & $3,13^{\text {ns }}$ \\
\hline CV (\%): & & 9,05 & 7,38 & 6,88 & 6,96 & 17,38 & 12,85 & 11,04 & 14,56 & 15,06 & 13,18 \\
\hline Média geral: & & 33,97 & 4,48 & 4,06 & 18,88 & 23,53 & 9,80 & 7,84 & 5,40 & 2,97 & 96,05 \\
\hline \multicolumn{2}{|c|}{ Substratos } & \multicolumn{5}{|c|}{$\mathrm{CR}(\mathrm{cm})$} & \multicolumn{5}{|c|}{ MFR (g muda ${ }^{-1}$ ) } \\
\hline \multicolumn{2}{|c|}{$40 \% \mathrm{CAC}+60 \% \mathrm{~EB}$} & \multirow{2}{*}{\multicolumn{5}{|c|}{$\begin{array}{l}15,73 \mathrm{c} \\
19,59 \mathrm{ba}\end{array}$}} & \multicolumn{5}{|c|}{$10,15 \mathrm{cba}$} \\
\hline \multicolumn{2}{|c|}{$100 \%$ SC } & & & & & & \multicolumn{5}{|c|}{$7,33 \mathrm{c}$} \\
\hline \multicolumn{2}{|c|}{$40 \% \mathrm{SC}+60 \% \mathrm{CAC}$} & \multicolumn{5}{|c|}{$18,55 \mathrm{cb}$} & \multicolumn{5}{|c|}{$8,78 \mathrm{cb}$} \\
\hline \multicolumn{2}{|c|}{$40 \% \mathrm{SC}+60 \% \mathrm{HM}$} & \multicolumn{5}{|c|}{$19,04 \mathrm{cba}$} & \multirow{2}{*}{\multicolumn{5}{|c|}{$\begin{array}{c}7,33 \mathrm{c} \\
12,37 \text { ba }\end{array}$}} \\
\hline \multirow{2}{*}{\multicolumn{2}{|c|}{$\begin{array}{l}40 \% \mathrm{SC}+60 \% \mathrm{~EB} \\
40 \% \mathrm{CAC}+60 \% \mathrm{HM}\end{array}$}} & \multicolumn{5}{|c|}{20,07 ba } & & & & & \\
\hline & & \multicolumn{5}{|c|}{$16,47 \mathrm{cb}$} & \multicolumn{5}{|c|}{13,50 a } \\
\hline \multicolumn{2}{|c|}{$40 \% \mathrm{HM}+60 \% \mathrm{~EB}$} & \multirow{2}{*}{\multicolumn{5}{|c|}{$\frac{22,73 a}{275}$}} & \multicolumn{5}{|c|}{$9,13 \mathrm{cb}$} \\
\hline \multicolumn{2}{|c|}{ DMS: } & & & & & & \multicolumn{5}{|c|}{3,60} \\
\hline
\end{tabular}

GL - Graus de liberdade. CV - Coeficiente de variação. DMS - Diferença mínima significativa. ${ }^{* *}$ Significativo a $1 \%$ de probabilidade, pelo teste F. ns - Não significativo. CAC - casca de arroz carbonizada; EB - esterco bovino; SC - substrato comercial; HM - húmus de mata. Médias seguidas por letras distintas na coluna diferem entre si pelo teste de Tukey, a $5 \%$ de probabilidade. ${ }^{*}=$ significativo a $5 \%$ de probabilidade; ${ }^{* *}=$ significativo a $1 \%$ de probabilidade; $\mathrm{ns}=$ não significativo.

Scalon et al. (2011), avaliando mudas de pau-ferro (Caesalpinia ferrea) em substratos, obtiveram resultados similares, de maior comprimento do sistema radicular, em substrato com menor teor de fósforo, alegando que a baixa disponibilidade induz um maior crescimento axial do sistema radicular em busca de nutrientes. Por outro lado, Duarte et al. (2016), comparando o uso de areia e vermiculita, mencionam que substratos de alta retenção de água, a exemplo da vermiculita, assim como do esterco bovino e da casa de arroz carbonizada utilizada nesta pesquisa, favorecem o desenvolvimento de mudas de Hymenaea courbaril L., onde melhores condições hídricas e nutricionais reduzem $\mathrm{o}$ tempo de formação das mudas.

O maior CR foi observado na mistura $40 \%$ húmus de mata $+60 \%$ esterco bovino, não se diferindo dos substratos de $40 \%$ SC $+60 \%$ EB, $40 \%$ SC $+60 \%$ HM e $100 \%$ SC. As análises químicas iniciais da mistura $40 \% \mathrm{HM}+60 \% \mathrm{~EB}$ (Tabela 1), em antecedência ao experimento, demonstram que a mesma apresenta $\mathrm{pH}$ neutro, igual a 7,0, e maior teor de potássio que os demais substratos, fatores estes que podem ter influenciado no $C R$, já que o potássio é um dos nutrientes que influencia na elongação celular e formação de raízes novas, tornando as mudas mais tolerantes ao déficit hídrico (POTAFOS,
1996). Em trabalho realizado por Barroso et al. (2005), a ausência de potássio em mudas de teca ocasionou redução no crescimento e na emissão de raízes novas. Silva et al. (2013), experimentando doses de potássio em substrato, na produção de mudas de cedro doce (Bombacopsis quinata), também constataram que maiores níveis de potássio propiciam mudas com maior biomassa seca de raízes e maior índice de qualidade das mudas.

Os demais parâmetros avaliados aos 50 dias, não apresentaram diferenças significativas (Tabela 3), devido em parte ao suprimento nutricional pelos cotilédones, conforme Dechoum (2004), até cerca de 30 dias após emergência, quando foi observada a sua abscisão das mudas.

Aos 70 dias após a semeadura (Tabela 4), não houve diferença significativa entre tratamentos, exceto no parâmetro de comprimento do sistema radicular, o qual apresentou maior expansão na mistura de $40 \%$ SC + $60 \% \mathrm{HM}$, não se diferindo dos substrato $100 \%$ SC e $40 \%$ SC + 60\% CAC, provavelmente em virtude dos altos teores de $\mathrm{Ca}, \mathrm{S}$ e $\mathrm{Mg}$ nesses substratos, e da alta porosidade, que segundo Silva et al. (2012) promove maior desenvolvimento do sistema radicular. Os substratos que propiciaram maior CR aos 70 dias foram distintos em comparação a 50 dias, e não 
continham esterco bovino em sua composição, possivelmente devido ao baixo teor de enxofre no esterco.

Os demais parâmetros avaliados aos 70 dias, apresentaram desenvolvimento semelhante entre tratamentos. Apesar dos substratos terem apresentado composição química diferenciada para $\mathrm{K}, \mathrm{Ca}, \mathrm{Mg}$ e $\mathrm{S}$, pouco influenciaram no desenvolvimento das mudas, certamente devido à baixa disponibilidade de $\mathrm{N}$ nas formas nítrica $\mathrm{e}$ amoniacal, uma vez que os materiais não se encontravam na forma totalmente mineralizada.

Tabela 4. Altura de muda (AM), número de folhas (NF), diâmetro do caule (DC), comprimento do sistema radicular (CR), massa fresca da parte aérea (MFPA), massa fresca de raízes (MFR), matéria seca da parte aérea (MSPA), de folhas (MSF) e de raízes (MSR) e área foliar (AF), aos 70 dias após semeadura, em função de substratos. Confresa-MT, 2015.

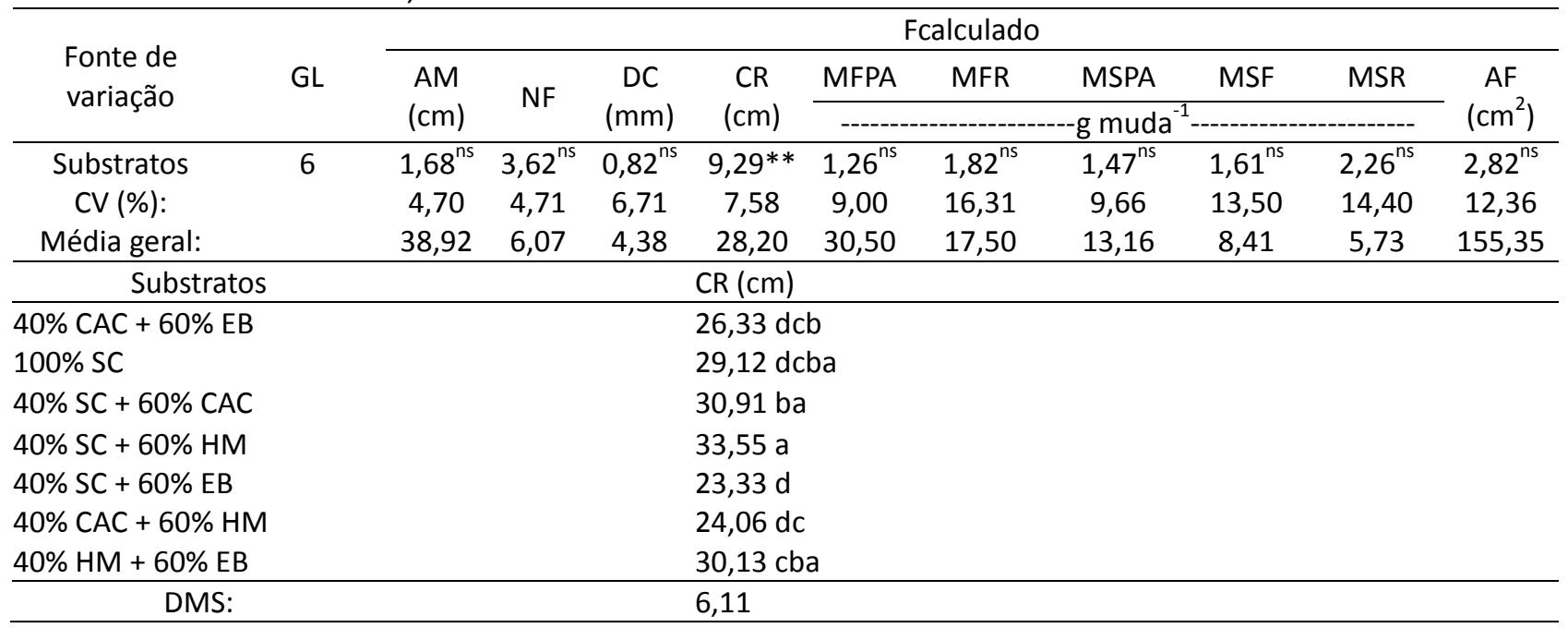

GL - Graus de liberdade. CV - Coeficiente de variação. DMS - Diferença mínima significativa. ${ }^{* *}$ Significativo a $1 \%$ de probabilidade, pelo teste F. ns - Não significativo. CAC - casca de arroz carbonizada; EB - esterco bovino; SC - substrato comercial; HM - húmus de mata. Médias seguidas por letras distintas na coluna diferem entre si pelo teste de Tukey, ao nível de $5 \%$ de probabilidade.

Na última avaliação, realizada aos 120 dias, outros parâmetros foram significativos $(p<0,05)$ em função dos substratos, como a altura de muda (AM), matéria seca de raízes (MSR) e teor de clorofila (CL), enquanto o número de folhas (NF), matéria fresca da parte aérea (MFPA) e área foliar (AF) apresentaram significância $p<0,01$ (Tabela 5). Maior AM foi observada na mistura de $40 \%$ húmus de mata $+60 \%$ esterco bovino, não se diferindo dos substratos $40 \% \mathrm{CAC}+60 \% \mathrm{HM}$ e $100 \%$ substrato comercial. Esses resultados provavelmente se deve à maior mineralização dos substratos à base de húmus de mata e esterco bovino $(40 \% \mathrm{HM}+60 \% \mathrm{~EB}, 40 \% \mathrm{CAC}+60 \% \mathrm{HM}$ e $40 \% \mathrm{SC}+60 \% \mathrm{~EB}$ ), maior disponibilidade de $\mathrm{N}$ nitrato aos 120 dias, do que nas fases iniciais, e maior disponibilidade de magnésio, nutriente este responsável pela constituição da molécula de clorofila. 
Tabela 5. Altura de muda (AM), número de folhas (NF), diâmetro do caule (DC), comprimento do sistema radicular (CR), massa fresca da parte aérea (MFPA), massa fresca de raízes (MFR), matéria seca da parte aérea (MSPA), de folhas (MSF) e de raízes (MSR), área foliar (AF) e índice de clorofila (CL), aos 120 dias após semeadura, em função de substratos. Confresa-MT, 2015.

\begin{tabular}{|c|c|c|c|c|c|c|c|c|c|c|}
\hline \multirow{3}{*}{$\begin{array}{l}\text { Fonte de } \\
\text { variação }\end{array}$} & \multirow{3}{*}{ GL } & \multicolumn{8}{|c|}{ Fcalculado } & \multirow{3}{*}{$\mathrm{CL}$} \\
\hline & & \multirow{2}{*}{$\begin{array}{l}\text { AM } \\
(\mathrm{cm})\end{array}$} & NF & \multirow{2}{*}{$\begin{array}{l}\mathrm{CR} \\
(\mathrm{cm})\end{array}$} & MFPA & MFR & MSPA & MSF & MSR & \\
\hline & & & $\begin{array}{c}\mathrm{DC} \\
(\mathrm{mm})\end{array}$ & & \multicolumn{3}{|r|}{--g muda ${ }^{-1}$} & & $\left(\mathrm{~cm}^{2}\right)$ & \\
\hline \multirow{3}{*}{$\begin{array}{l}\text { Substratos } \\
\text { CV (\%): } \\
\text { Média geral: }\end{array}$} & \multirow[t]{3}{*}{6} & $7,23 * 1$ & $\begin{array}{cc}12,80^{*} & 1,54^{n} \\
* & s\end{array}$ & $7,37^{*}$ & $11,43^{* *}$ & $1,20^{\text {ns }}$ & $3,23^{\text {ns }}$ & $6,33^{*}$ & $\begin{array}{c}11,34^{*} \\
*\end{array}$ & * $8,44 *$ \\
\hline & & 6,53 & $9,86 \quad 5,74$ & 13,92 & 10,11 & 21,14 & 16,71 & 16,96 & 22,68 & 8,37 \\
\hline & & 44,71 & 6,95 & 24,19 & 47,01 & 27,35 & 23,07 & 18,61 & 372,39 & 41,31 \\
\hline \multirow{2}{*}{\multicolumn{2}{|c|}{ Substrato }} & \multirow{2}{*}{$\begin{array}{l}\text { AM } \\
(\mathrm{cm})\end{array}$} & \multirow{2}{*}{$\mathrm{NF}$} & \multirow{2}{*}{$\begin{array}{c}\mathrm{CR} \\
(\mathrm{cm}) \\
\end{array}$} & \multirow{2}{*}{\multicolumn{2}{|c|}{ MFPA }} & MSF & MSR & \multirow{2}{*}{$\begin{array}{c}\mathrm{AF} \\
\mathrm{cm}^{2} \mathrm{muda}^{-1}\end{array}$} & $\mathrm{CL}$ \\
\hline & & & & & & & ---g muda ${ }^{-1}$ & -------- & & - \\
\hline \multicolumn{2}{|l|}{$40 \% \mathrm{CAC}+60 \% \mathrm{~EB}$} & $40,48 \mathrm{c}$ & $5,66 \mathrm{c}$ & $20,22 \mathrm{cba}$ & \multicolumn{2}{|c|}{$40,02 \mathrm{c}$} & $15,25 \mathrm{cb}$ & $8,31 \mathrm{c}$ & $234,68 \mathrm{~b}$ & $38,56 \mathrm{cb}$ \\
\hline \multicolumn{2}{|l|}{$100 \%$ SC } & \multirow{2}{*}{$44,43 \mathrm{cba}$} & $6,72 c$ & 29,58 a & \multicolumn{2}{|c|}{$44,81 \mathrm{cb}$} & $16,61 \mathrm{cba}$ & $9,62 \mathrm{cba}$ & $289,84 \mathrm{~b}$ & $37,70 \mathrm{cb}$ \\
\hline \multirow{2}{*}{\multicolumn{2}{|c|}{$\begin{array}{l}40 \% \text { SC }+60 \% \text { CAC } \\
40 \% \text { SC }+60 \% \mathrm{HM}\end{array}$}} & & $5,77 \mathrm{c}$ & $29,70 \mathrm{a}$ & 38,5 & $58 \mathrm{c}$ & $13,27 \mathrm{c}$ & $8,77 \mathrm{cb}$ & 209,18 b & $34,01 \mathrm{c}$ \\
\hline & & $43,21 \mathrm{cb}$ & $6,94 \mathrm{cb}$ & $26,73 \mathrm{cba}$ & 43,0 & $66 \mathrm{cb}$ & 19,21 & $12,13 \mathrm{cba}$ & a $350,34 b$ & $39,82 \mathrm{cb}$ \\
\hline & & $42,81 \mathrm{cb}$ & $5,77 c$ & $17,31 \mathrm{c}$ & 42,9 & $90 \mathrm{cb}$ & $16,37 \mathrm{cb}$ & $8,12 \mathrm{c}$ & 317,91 & 41,43 \\
\hline $40 \% \mathrm{SC}+60 \% \mathrm{~EB}$ & & & & & & & & & & cba \\
\hline $40 \% \mathrm{CAC}+60 \% \mathrm{HN}$ & & $49,50 \mathrm{ba}$ & 8,72 ba & $18,71 \mathrm{cb}$ & 56,0 & $44 \mathrm{ba}$ & 23,98 ba & $13,70 \mathrm{ba}$ & $594,14 a$ & $46,39 \mathrm{ba}$ \\
\hline $40 \% \mathrm{HM}+60 \% \mathrm{~EB}$ & & $52,25 \mathrm{a}$ & $9,05 a$ & 27,06 ba & 63,6 & 66 a & 25,56 a & $14,72 \mathrm{a}$ & $610,67 a$ & 51,31 a \\
\hline DMS & & 8,34 & 1,95 & 9,62 & 13, & 58 & 9,02 & 5,13 & 241,57 & 9,88 \\
\hline
\end{tabular}

Os substratos à base de húmus de mata e esterco bovino apresentam em sua composição elevados teores de $\mathrm{N}$ e matéria orgânica, a qual propicia alta retenção de água, favorecendo os parâmetros da AF, NF e CL. Conforme a análise dos substratos, ao término do experimento (Tabela 6), uma fração do nitrogênio (N) e potássio (K) disponível nos substratos foram absorvidos pelas mudas. A alta disponibilidade de potássio $(\mathrm{K})$, magnésio $(\mathrm{Mg})$ e $\mathrm{N}$-Nitrato em três substratos $(40 \% \mathrm{HM}+60 \% \mathrm{~EB}, 40 \% \mathrm{SC}+60 \% \mathrm{~EB}$ e $40 \%$ CAC + 60\% HM), certamente favoreceu processos fisiológicos como a transpiração, a fotossíntese, aumento do índice de clorofila e, consequentemente, a síntese de $\mathrm{CO}_{2}$, a área foliar e a massa seca de folhas.

Os resultados de maior altura de muda em $40 \% \mathrm{HM}+60 \% \mathrm{~EB}$, aos 70 e 120 dias, corroboram aos obtidos por Carvalho Filho et al. (2003), sobretudo devido ao $\mathrm{N}$ disponibilizado através do esterco nas formas nítrica e amoniacal. Esses autores avaliaram o desenvolvimento de mudas de jatobá, e concluíram que os melhores resultados de AM foram obtidos utilizando substrato constituído de solo, areia e esterco bovino, na proporção 1:2:1. Gonzaga et al. (2016), experimentando dez composições de substrato, concluíram que a mistura de $60 \%$ solo $+20 \%$ areia $+20 \%$ de cama de aviário propiciou maior incremento de biomassa de mudas de Hymenaea courbaril L. Materiais como o húmus de mata, o esterco bovino e a cama de aviário, que apresentam altas concentrações de $\mathrm{N}$-nitrato após mineralização da matéria orgânica, apresentam influência significativa no crescimento e ganho de biomassa das mudas, sobretudo a partir de 70 DAS.

Os maiores valores de $\mathrm{CR}$ aos 120 dias foram observados em $100 \%$ SC e $40 \%$ SC $+60 \%$ CAC, os quais podem, em parte, ser atribuídos aos altos teores de $\mathrm{Ca}^{2+}$ e enxofre $\left(\mathrm{SO}_{4}{ }^{-}\right)$, apresentados nesses substratos, que por sua vez induzem maior desenvolvimento do sistema radicular em termos de comprimento. Esses resultados divergem da avaliação aos 70 dias, certamente devido à maior ou menor disponibilidade de nutrientes em cada substrato, que depende de parâmetros como a razão $\mathrm{C} / \mathrm{N}$ e $C / P$, fundamentais na mineralização da matéria orgânica. Os resultados de CR contrariam os obtidos por Scalon et al. (2011), que avaliando o crescimento de pau-ferro (Caesalpinia ferrea) em diferentes substratos, afirmaram o maior $C R$ na mistura terra + areia se deve à baixa 
disponibilidade de nutrientes e água nesse substrato, induzindo maior crescimento axial das raízes em busca de nutrientes.

Por outro lado, maior MFPA $(p<0,01)$ e massa seca de folhas (MSF) foram obtidos com utilização de 40\% HM + 60\% EB (Tabela 5), não diferindo estatisticamente de $40 \%$ CAC $+60 \%$ $\mathrm{HM}, 40 \% \mathrm{SC}+60 \% \mathrm{HM}$ e $100 \% \mathrm{SC}$. Este resultado vem a confirmar a maior altura de planta, número de folhas e área foliar na mistura de $40 \% \mathrm{HM}+$ $60 \%$ EB. Os demais tratamentos não se diferiram estatisticamente, nos parâmetros de MFR, massa seca da parte aérea (MSPA) e diâmetro de caule (DC).

Os parâmetros MSF e MSR, aos 120 dias, apresentaram melhores resultados no substrato composto de $40 \% \mathrm{HM}+60 \% \mathrm{~EB}$, assim como a área foliar (AF) não diferindo do substrato composto de $40 \% \mathrm{CAC}+60 \% \mathrm{HM}$. A presença em quantidade ótima de nutrientes essenciais nesses substratos, na fase inicial das plântulas, favoreceu o desenvolvimento radicular e foliar das mudas, com destaque aos macronutrientes $\mathrm{N}$ e $\mathrm{K}$, os quais contribuíram para a obtenção desses resultados. A diferença na área foliar das mudas, entre substratos, somente foi constatada na última avaliação, quando já tinha ocorrido a abscisão dos cotilédones e uma fração do Norgânico já se encontrava na forma de N-nitrato. Nesses substratos também foram obtidos maiores índices de clorofila nas folhas, índices estes influenciados, sobretudo, pela disponibilidade de nitrogênio, ferro e magnésio nos substratos.

Os resultados obtidos no presente trabalho se devem principalmente à composição do substrato ter reunido características físicas e químicas que promovem a disponibilidade de nutrientes e a retenção de água, fatores estes essenciais ao desenvolvimento das mudas, sobretudo na fase de 70 a 120 dias, quando os substratos à base de esterco bovino e húmus de mata apresentaram maior disponibilidade $\mathrm{N}$ nitrato, devido à mineralização da matéria orgânica. Parte dos nutrientes foi assimilada pelas mudas, uma vez que as análises, ao final do experimento, indicaram menor concentração para determinados nutrientes, como potássio, enxofre, fósforo e magnésio (Tabela 6), em relação às análises realizadas em antecedência à semeadura (Tabela 1).

Tabela 6. Resultado de análises químicas de macro e micronutrientes, potencial hidrogeniônico (pH), condutividade elétrica (CE) de misturas de substratos ao término do experimento, aos 120 dias após semeadura do jatobazeiro (Hymenaea courbaril L.), Confresa-MT, 2015.

\begin{tabular}{|c|c|c|c|c|c|c|c|c|c|c|c|c|c|c|c|c|}
\hline \multirow[t]{2}{*}{ Substrato } & \multirow[t]{2}{*}{$\mathrm{pH}$} & $\mathrm{CE}$ & $\begin{array}{c}\mathrm{N}- \\
\text { Nitrato } \\
\end{array}$ & $P$ & $\mathrm{Cl}$ & $\mathrm{S}$ & $\begin{array}{c}\mathrm{N}- \\
\text { Amônia }\end{array}$ & $\mathrm{K}$ & $\mathrm{Na}$ & $\mathrm{Ca}$ & $\mathrm{Mg}$ & B & $\mathrm{Cu}$ & $\mathrm{Fe}$ & $\mathrm{Mn}$ & $\mathrm{Zn}$ \\
\hline & & $\mathrm{dS} / \mathrm{m}$ & \multicolumn{14}{|c|}{$\mathrm{mg} \mathrm{L}^{-1}$} \\
\hline $00 \%$ SC & 6,2 & 0,3 & 1,8 & & 0 & & 5,6 & 8,2 & 19,6 & 11,8 & 7,1 & & & & & \\
\hline $10 \% \varsigma$ & & & 2,2 & & 32,3 & & $2, c$ & 3,8 & 13,7 & 10,7 & 1,4 & & 0,02 & 15,5 & & \\
\hline $\mathrm{SC}$ & & 0,2 & 0,5 & 6,6 & 0,0 & 17,0 & 1,4 & 7,8 & 15,4 & 10,6 & 1,4 & 0,04 & 0,02 & 5,2 & & 0,0 \\
\hline $40 \% \mathrm{~S}$ & 3 & 0,6 & 60,2 & 25,1 & 2,5 & 8,6 & 5,6 & 67,7 & 34,0 & 45,8 & 32,2 & 0,1 & 0,02 & 0,3 & 01 & 0,0 \\
\hline $40 \% \mathrm{C}$ & & 0,1 & 5,7 & 0,6 & 3, & 4,5 & 1,3 & 7,1 & 8,4 & 14,3 & 0,9 & 0,03 & 0,02 & 14,3 & $<0,01$ & 0,0 \\
\hline & & 0,6 & 33,6 & 17,1 & 1,1 & 48,0 & 3,9 & 24,7 & 24,2 & 52,1 & 27,6 & 0,1 & 0,03 & 0,5 & & 0,0 \\
\hline $0 \% \mathrm{HM}+60 \% \mathrm{~EB}$ & 6,4 & 0,5 & 4,5 & 1,9 & 5,3 & 6,2 & 4,9 & 58,1 & 38,9 & 1,8 & 12,0 & 0,1 & 0,02 & 2,2 & $<0,01$ & 0,0 \\
\hline
\end{tabular}

SC - substrato comercial; HM - húmus de mata; CAC - casca de arroz carbonizada; EB - esterco bovino.

Os nutrientes $\mathrm{K}, \mathrm{S}, \mathrm{P}$ e $\mathrm{Mg}$ são responsáveis pela transpiração, síntese de aminoácidos e proteínas, armazenamento e transferência de energia, composição da clorofila, respectivamente, dentre outras funções, conforme Souza et al. (2010), Inocêncio et al. (2014), Duarte et al. (2015), os quais estão relacionados à síntese de $\mathrm{CO}_{2}$ e ao acúmulo de matéria seca, que varia nas fases de 50, 70 e 120 dias. Souza et al. (2010) verificaram que, dentre os macronutrientes, o fósforo foi o que mais limitou o desenvolvimento de mudas de mogno (Swietenia macrophylla King.) e a matéria seca de raízes e parte aérea, assim como a absorção de outros nutrientes, sendo $O$ requerimento nutricional em macronutrientes de $\mathrm{P}>\mathrm{S}>\mathrm{K}>\mathrm{N}$, em ordem decrescente. 


\section{Conclusões}

Para a produção de mudas de jatobazeiro, recomenda-se fazer superação de dormência de sementes por meio de escarificação com lixa e imersão em água por 24 horas.

Dentre os substratos utilizados, a mistura de $40 \%$ de húmus de mata $+60 \%$ de esterco bovino propicia mudas mais vigorosas, sobretudo aos 120 dias após semeadura, quando já ocorreu abscisão de cotilédones e mineralização da matéria orgânica.

\section{Referências}

ANDRADE, L.A.; BRUNO, A.L.R.; OLIVEIRA, B.S.L.; SILVA, F.T.H. Aspectos biométricos de frutos e sementes, grau de umidade e superação de dormência de jatobá. Acta Scientiarum Agronomy, v.32, n.2, 293-299, 2010. https://doi.org/10.4025/actasciagron.v32i2.3681

ATAÍDE, G.M.; BICALHO, E.M.; DIAS, D.C.F.S.; CASTRO, R.V.O.; ALVARENGA, E.M. Superação da dormência das sementes de Delonix regia (Bojer ex Hook.) Raf. Revista Árvore, v.37, n.6, p.11451152, 2013. https://doi.org/10.1590/S0100$\underline{67622013000600016}$

BARROSO, D.G.; FIGUEIREDO, F.A.M.M.A.; PEREIRA, R.C.; MENDONÇA, A.V.R.; SILVA, L.C. Diagnóstico de deficiências de macronutrientes em mudas de teca. Revista Árvore, v.29, n.5, p.671-679, 2005. https://doi.org/10.1590/S0100$\underline{67622005000500002}$

BUSATTO, P.C.; NUNES, A.S.; COLMAN, B.A.; MASSON, G.L. Superação de dormência em sementes de jatobá (Hymenaea courbaril L.). Revista Verde de Agroecologia e Desenvolvimento Sustentável, v.8, n.1, p.154160, 2013.

CABRAL, E.M.S.; CASTILHO, R.M.M.; PAGLIARINI, M.K. Germinação de sementes e desenvolvimento de mudas de jatobá (Hymenaea courbaril L. var. Stilbocarpa). Revista Eletrônica Thesis, ano xi, n.23, p.16-28, 2015. Disponível em:

http://www.cantareira.br/thesis2/ed_23/materia 2.pdf

CARVALHO FILHO, J.L.S.; ARRIGONI-BLANK, M.F.; BLANK, A.F.; RANGEL, M.S.A. Produção de mudas de jatobá (Hymenaea courbaril L.) em diferentes ambientes, recipientes e composições de substratos. Cerne, v.9, n.1, p.109-118, 2003.

COELHO, T.B.; RIBEIRO, V.A. Superação de dormência em sementes de jatobá. Ipê Agronomic Journal, v.2, n.1, p.14-22, 2018.

ROS, C.O.; REX, F.E.; RIBEIRO, I.R.; KAFER, P.S.; RODRIGUES, A.C.; SILVA, R.F.; SOMAVILLA, L. Uso de substrato compostado na produção de mudas de Eucalyptus dunnii e Cordia trichotoma. Floresta e Ambiente, v.22, n.4, p.549-558, 2015. https://doi.org/10.1590/2179-8087.115714

DECHOUM, M.S. Crescimento inicial, alocação de recursos e fotossíntese em plântulas adubação com potássio e enxofre. Ciência Florestal, v.25, n.1, p.221-229, 2015. https://doi.org/10.5902/1980509817480

DUARTE, M.M.; PAULA, S.R.P.; FERREIRA, F.R.L.; NOGUEIRA, A.C. Morphological characterization of fruit, seed and seedling and germination of Hymenaea courbaril L. (Fabaceae) ('Jatobá'). Journal of Seed Science, v.38, n.3, p.204-211, $2016 . \quad$ https://doi.org/10.1590/2317$\underline{1545 \mathrm{v} 38 \mathrm{n} 3159734}$

FARIAS, D.C.; MATA, M.E.R.M.C.; DUARTE, M.E.M.; LIMA, A.K.V.O. Qualidade fisiológica de sementes de jatobá submetidas a diferentes temperaturas criogênicas. Revista Brasileira de Produtos Agroindustriais, v.8, n.1, p.67-74, 2006. https://doi.org/10.15871/15178595/rbpa.v8n1p67-74

FERREIRA, D.F. SISVAR: a computer statistical analysis system. Ciência e Agrotecnologia, v.35, n.6, p.1039-1042, 2011. https://doi.org/10.1590/S1413$\underline{70542011000600001}$

FERREIRA, W.C.; FREITAS, D.V.; DIAS, D.P.; BOTELHO, S.A. Crescimento de espécies arbóreas plantadas em área de exploração de cascalho em usina hidrelétrica. Enciclopédia Biosfera, v.13, n.24, p.340-353, 2016. https://doi.org/10.18677/EnciBio 2016B 031

FREITAS, A.R.; LOPES, J.C.; MATHEUS, M.T.; MENGARDA, L.H.G.; VENANCIO, L.P.; CALDEIRA, M.V.W. Superação da dormência de sementes de jatobá. Pesquisa Florestal Brasileira, v.33, n.73, p.85-90,

2013. 
GONZAGA, L.M.; SILVA, S.S.; CAMPOS, S.A.; FERREIRA, R.P.; CAMPOS, A.N.R.; CUNHA, A.C.M.C.M. Recipientes e substratos para a produção de mudas de jatobá (Hymenaea courbaril L.). Revista Brasileira de Agropecuária Sustentável, v.6, n.1, p.64-73, 2016. https://doi.org/10.21206/rbas.v6i1.309

INOCÊNCIO, M.F.; CARVALHO, J.G.; FURTINI NETO, A.E. Potássio, sódio e crescimento inicial de espécies florestais sob substituição de potássio por sódio. Revista Árvore, v.38, n.1, p.113-123, 2014. https://doi.org/10.1590/S0100$\underline{67622014000100011}$

LAHR, F.A.R.; CHRISTOFORO, A.L.; SILVA, C.E.G.; ANDRADE JUNIOR, J.R.; PINHEIRO, R.V. Avaliação de propriedades físicas e mecânicas de madeiras de Jatobá (Hymenaea stilbocarpa Hayne) com diferentes teores de umidade e extraídas de regiões distintas. Revista Árvore, v.40, p.147-154, $2016 . \quad$ https://doi.org/10.1590/0100$\underline{67622016000100016}$

MAGUIRE, J.D. Speeds of germination - aid in selection and evaluation for seedling emergence and vigor. Crop Science, v.2, n.2, p.176-177, 1962.

https://doi.org/10.2135/cropsci1962.0011183X00 $\underline{0200020033 x}$

MONACO, P.A.V.; ROLDI JUNIOR, G.; HADDADE, I.R.; KRAUSE, M.R.; GUISOLFI, L.P.; ALMEIDA, K.M. Reuse of residues as substrate for production of eucalyptus (Eucalyptus urograndis) seedlings. Floresta e Ambiente, v.27, n.3, p.1-7, 2020. https://doi.org/10.1590/2179-8087.014018

NASCIMENTO, H.H.C.; NOGUEIRA, R.J.M.C.; SILVA, E.C.; SILVA, M.A. Análise do crescimento de mudas de jatobá (Hymenaea courbaril L.) em diferentes níveis de água no solo. Revista Árvore, v.35, n.3, p.617-626, 2011. https://doi.org/10.1590/S0100-

$\underline{67622011000400005}$

POTAFOS. Manual internacional de fertilidade do solo. 2. ed. Piracicaba: Potafos, 1996. 177p.

SAMPAIO, M.F.; COUTO, S.R.; SILVA, C.A.; SILVA, A.C. A.; SILVA, A.A.S.; TEIXEIRA, A.L. Influência de diferentes substratos associados a métodos de superação de dormência na germinação e emergência de sementes de jatobá (Hymenaea courbaril L.). Revista Farociência, v.2, n.1, p.1127, 2015. https://doi.org/10.36703/farociencia.v3i1.94

SCALON, S.P.Q.; TEODÓSIO, T.K.C.; NOVELINO, J.O.; KISSMANN, C.; MOTA, L.H.S. Germinação e crescimento de Caesalpinia férrea Mart. Extul. em diferentes substratos. Revista Árvore, v.35, n.3, p.633-639, 2011. https://doi.org/10.1590/S0100$\underline{67622011000400007}$

SILVA, C.A.; DOURADO NETO, D.; SILVA, C.J.; FREITAS, C.A. Development of Hymenaea courbaril seedlings in function of containers and irrigation blades. Revista Árvore, v.40, n.3, p.487498, 2016. https://doi.org/10.1590/0100$\underline{67622016000300012}$

SILVA, P.M.C.; UCHÔA, S.C.P.; BARBOSA, J.B.F.; BASTOS, V.J.; ALVES, J.M.A.; FARIAS, L.C. Efeito do potássio e do calcário na qualidade de mudas de cedro doce (Bombacopsis quinata). Revista Agro@mbiente, v.7, n.1, p.63-69, 2013. https://doi.org/10.18227/1982-

8470ragro.v7i1.842

SILVA, R.B.G.; SIMÕES, D.; SILVA, M.R. Qualidade de mudas clonais de Eucalyptus urophylla $\times E$. grandis em função do substrato. Revista Brasileira de Engenharia Agrícola e Ambiental, v.16, n.3, p.297-302, 2012. https://doi.org/10.1590/S1415$\underline{43662012000300010}$

SOUZA, V.M.S.; SEGATO, S.V. Superação de dormência em sementes de jatobá (Hymenaea courbaril L.). Nucleus, v.13, n.1, p.71-80, 2016. https://doi.org/10.3738/1982.2278.1616

SOUZA, C.A.S.; TUCCI, C.A.F.; SILVA, J.F.; RIBEIRO, W. O. Exigências nutricionais e crescimento de plantas de mogno (Swietenia macrophylla King.). Acta Amazônica, v.40, n.3, p.515-522, 2010. https://doi.org/10.1590/S0044$\underline{59672010000300010}$

TELES, M.M.; ALVES, A.A.; OLIVEIRA, J.C.G.; BEZERRA, A.M.E. Métodos para quebra da dormência em sementes de leucena (Leucaena leucocephala Lam.) de wit. Revista Brasileira de Zootecnia, v.29, n.2, p.387-391, 2000. https://doi.org/10.1590/S1516-

$\underline{35982000000200010}$ 